\title{
Los concursos en España: percepción histórica y evolución del género (1956-1975)
}

\author{
Julio Moreno DíAz \\ Universidad Rey Juan Carlos \\ julio.moreno@urjc.es
}

Recibido: $04 / 02 / 2014$

Aceptado: 10/03/2014

\section{Resumen}

El concurso ha sido uno de los contenidos audiovisuales con mayor presencia a lo largo de la historia de la televisión mediante producciones que ofrecieron en sus narraciones un imaginario donde la puesta en escena y la gesta de los participantes lo convirtieron en el paradigma del entretenimiento televisivo. El presente artículo parte de esta premisa para analizar su importancia como referente histórico en televisión con un recorrido a través de sus formas de representación desde el inicio de la pequeña pantalla hasta los albores de la Transición en España.

Palabras clave: Concurso, entretenimiento, televisión, programación, formatos, TVE.

\section{Spanish quizzes and games shows: evolution and historical perception} (1956-1975)

\begin{abstract}
The quizzes and games shows have been a greater presence audiovisual throughout the history of television productions offered by their imaginary narratives where the staging and the exploits of the participants made it the paradigm of television entertainment. This article starts with this premise to confirm its importance as a historical reference on television with a journey through their representational forms from the beginning of the small screen to the beginning of the Transition in Spain.
\end{abstract}

Keywords: Quiz show, entertainment, television programming, game show, TVE, Spain

Referencia normalizada: MORENO DÍAZ, Julio (2014): "Los concursos en España: percepción histórica y evolución del género (1956-1975)". Estudios sobre el Mensaje Periodístico, Vol. 20, Núm. especial, pp. 27-42. Madrid, Servicio de Publicaciones de la Universidad Complutense

Sumario: 1. Introducción y objetivos. 2. Hipótesis. 3. Metodología. 4. Los primeros concursos. 5. La espectacularización de los formatos. 6. Conclusiones. 7. Referencias.

\section{Introducción y objetivos}

A pesar de que la televisión presenta diferentes modalidades y criterios que configuran su estudio es, en general, su programación la que ha ido orientando la organización de su historia con especial protagonismo de los formatos de carácter lúdico. Así, la televisión del entretenimiento se ha establecido como uno de los más claros referentes en la disposición de la percepción histórica de la recepción televisiva. El entretenimiento se convirtió en la fórmula más eficaz para popularizar los contenidos de una inaugurada programación donde los espacios musicales y de variedades se convirtieron en uno de los ejes vertebrales de la parrilla hasta que el concurso lideró el modelo espectacular de la cadena tras adquirir su propia autonomía.

Normalmente, el atractivo de los concursos está fundamentado en la "implicación emotiva" del espectador (Ferrés, 1996: 136) con el juego de los participantes y en la presentación de contenidos aptos para todo tipo de público. Aspecto estrechamente 
relacionado con el poder socializador de la pequeña pantalla y de su marcado carácter familiar que potencia la "práctica de ver la televisión" (Morley, 1996: 56) estimulando una nueva cita/proposición con el espectador. Una seducción entendida como el "principio organizador del tiempo de numerosos espectadores" (Augé, 1998: 162) que argumenta la memoria generacional de muchos cuyas experiencias personales televisivas suponen un "fenómeno de significado sociocultural" (Hurtley, 2000: 174). Este poder ritualizador de la televisión propio de la "paleotelevisión" (Eco, 1985: 210) equiparó "la historia social de cada uno con la historia de TVE y a su vez con la de nuestra sociedad" (Baget, 1975: 10) extendiendo nuevas costumbres, ritos y actitudes ligados a la cultura del consumo masivo. La televisión se convierte en un "espejo de la sociedad" (Wolton, 1995: 96) creando un vínculo con todos aquellos que la miran simultáneamente.

La relación televisión-familia y el contenido lúdico de los concursos sirvieron, por tanto, para entender al entretenimiento televisivo como una fórmula con la que invertir el tiempo libre. La televisión pública se alzó como el medio principal en la difusión de ocio a través de una oferta basada en la espectacularización de los concursos y programas de variedades como resultado de los estrenos de la producción de los estudios de Prado del Rey en Madrid, complementados con los de Miramar en Barcelona, que enriquecieron la oferta y aumentaron la demanda.

De este modo, el perfeccionamiento de los contenidos junto a la proliferación general de televisores en los hogares nacionales confirió al concurso de un marcado carácter popular tras la mediatización de sus modelos y mecánicas que han sido empleados y transformados hasta la actualidad. Así, su evolución ha estado condicionada por su versatilidad que indica la riqueza formal del mismo (expresada a través de las mejoras del lenguaje audiovisual y su correspondiente puesta en escena así como otros atractivos ofertados: premios, presentadores...) y le configuran como el referente de los programas de entretenimiento. Por lo tanto, la producción de los concursos es fundamental para esbozar el contexto televisivo de una etapa histórica (19561975) marcada por las dependencias del Régimen y el monopolio audiovisual imperante.

Tal y como reflejan los paneles de aceptación de programas publicados por la revista Tele Radio (1956-1975), los espacios de entretenimiento eran los preferidos por los espectadores, formatos alejados de las entrevistas políticas o informativos de la propaganda franquista, propios de la época. Por consiguiente, es objetivo de esta investigación, reflejar el protagonismo del poder dinamizador de la programación de entretenimiento para alejarse de la concepción global y genérica que primariamente se tiene de este periodo.

Este objetivo es completado a través del análisis y evolución de los programas concursos entendidos como los mayores representantes del entretenimiento televisivo. Principalmente por dos factores: son el reflejo de la misma evolución de la televisión (tecnológica y socialmente) y su recepción es altamente popular con una capacidad significativa para atraer e influir en todo tipo de público (marcas comerciales, estilo de vida, internacionalización de modismos, star system...). De este modo, no sólo se pretende demostrar la legitimación como estudio cultural a la historia de la televisión 
de entretenimiento sino dotar también a los programas concursos de un papel relevante en la cimentación de la programación de TVE con respecto a los de variedades y variantes.

Para ello, el concurso es estudiado desde el punto de vista de la producción de los estándares y tipos de contenidos en el objetivo de precisar las directrices que han marcado su evolución a través de los rasgos formales y estructurales de su organización.

Así se elaborará un análisis de los diferentes formatos destacando las líneas maestras y elementos de su marca de autor que progresivamente han pasado a formar parte como propias y comunes del resto de producciones. Una investigación de interés general que aporta información detallada para servir como complemento y referente en las investigaciones sobre la historia de la televisión en España y al entretenimiento histórico audiovisual.

\section{Hipótesis}

Una vez establecido el punto de partida de la investigación se llegó a la conclusión de que para abordar el tema original y central era fundamental y necesario analizar íntegramente la programación de entretenimiento en las parrillas de programación desde 1956 hasta 1975. No existe un listado o censo previo de concursos televisivos que facilitara el buen hacer del estudio. Tan sólo las clásicas referencias a los formatos más populares y de una manera muy genérica. Por tanto, la búsqueda de programas concurso (centralizada en sus mecánicas y dinámicas y estándares de producción determinados por su evolución natural como contenido televisivo) constituye el núcleo de la investigación. Lo primero fue constatar la documentación existente para establecer una clasificación genérica de los originarios formatos emitidos; momento en el que se plantea la primera cuestión: ¿A qué razones (de programación y producción) responden los concursos en los inicios de la programación de TVE? Interrogante al que se sumarían otros relacionados con su paulatino perfeccionamiento (o no) hasta la fecha clave de final del Régimen en 1975, así como el número total de producciones.

Generalmente, cuando se acometen investigaciones históricas televisivas durante este periodo se parte de las supuestas carencias del medio (tecnológicas, económicas, profesionales...) y de la determinación de la imposición ideológica franquista. Contexto que hace aún más atractivo el estudio de formatos lúdicos que contrastan con la concepción de esa televisión gris y política que fue coloreada con grandes dosis de esparcimiento y distracción.

\section{Metodología}

Establecido el objeto de estudio y citadas las líneas generales que dirigirán al presente artículo, se concreta y se justifica la metodología seguida para su desarrollo. El punto de partida fue la obtención de los datos que responden al período de estudio comprendido entre los años 1956 y 1975 . Estas fechas guardan relación con dos capítulos históricos de referencia: la inauguración y las primeras emisiones regulares de TVE y el cambio de régimen hacia un estado democrático en España que implicó cambios en lo establecido inaugurando una nueva etapa en todos los ámbitos, y particularmente, en la producción de la cadena estatal. Esta disposición temporal ha servido 
para confirmar la existencia de emisiones que testifican su importancia en la evolución histórica de la pequeña pantalla.

Para la recopilación de información se empleó la principal y única fuente de información completa y disponible sobre programación y actualidad televisiva desde los primeros años de TVE: la revista Tele Radio (hasta 1960 denominaba Telediario) gracias al fondo documental de la Biblioteca Nacional, Hemeroteca Municipal de Madrid e Instituto de Radiotelevisión Española. Se trata de una publicación oficial y semanal de la Corporación de RTVE donde se expone la programación diaria de televisión y radio junto con otras secciones. Una fuente relevante que servía para el fomento del medio y la relación de éste con sus receptores. De esta manera, la revista se convierte en la guía principal para la investigación.

El primer cometido fue el estudio de todas y cada una de las programaciones semanales publicadas para concluir con el número total de concursos emitidos. Para ello se parte de la primera edición de Telediario en diciembre de 1957 (publicaciones 1105) para continuar con la Tele Radio a partir de 1960 (publicaciones 106-941). Tras una exhaustiva lectura, se localizaba el espacio y se volcaba a una base de datos en la que se señalaba lo siguiente: título; año de producción; duración total; día de emisión; hora de emisión; final de producción; etapa; total emisiones; tipo de producción; y una descripción detallada de su dinámica, mecánica y producción que sirviera para reconocer en perspectiva la evolución de los programas. Para este último apartado fue imprescindible el resumen que Tele Radio incorporaba en las programaciones semanales así como otros documentos en torno al formato: reportajes sobre el estreno o finalización, entrevistas a presentadores y/o concursantes, críticas, artículos, panel de aceptación, cartas al director... También cobran especial notabilidad las fotografías que acompañan a tales artículos entendidas como la única fuente visual del programa debido a la falta de conservación y documentación.

A partir del estudio del año 1966, la investigación es complementada por la revista Teleprograma (publicaciones 1-459) inaugurando una nueva fase en la obtención de datos. Esta nueva publicación serviría para corroborar y ampliar informaciones obtenidas de Tele Radio. Igualmente y a lo largo de todo el periodo, se emplearía el archivo digital de los periódicos $A B C$ y La Vanguardia (1956-1975) así como los 23 fascículos dominicales editados por el Diario Ya a partir de abril de 1987 y, especialmente, algunas publicaciones rigurosas en el ámbito de la historia de la Televisión en España. Además, se han consultado documentos en red (entrevistas, piezas audiovisuales, material iconográfico) que han complementado a la información suministrada por las fuentes citadas y que han confirmado la difusión social y popular de algunas producciones. Esta recopilación de información constituyó una etapa importante de la investigación.

Una vez diseñada la base de datos personal con fechas precisas y un elaborado análisis de contenido, se procede al visionado de los fondos audiovisuales de RTVE que ha permitido tener un enfoque enormemente preciso de los concursos. Las búsquedas previas (Tele Radio, Teleprograma) han resultado de gran importancia ya que han facilitado enormemente las búsquedas en el archivo por parte de sus responsables, los cuales, facilitaron los programas conservados en formato Betacam junto a una 
descripción técnica de utilidad. No obstante, la falta de muchos de los programas (debido a la inicial carencia de conciencia de memoria histórica) ha sido un claro obstáculo en el desarrollo de la metodología. Son pocos los programas que se conservan en su totalidad. La mayoría presentan bloques de grabación incompletos.

Tras el visionado, se incorpora mayor información a la base elaborada inicialmente teniendo en cuenta los siguientes parámetros: puesta en escena (escenografía, iluminación, títulos); realización; ambientación sonora; protagonismo presentador y concursante; desarrollo del juego; papel del espectador, influencias; y estándar de producción. Elementos que dotan a la investigación de una mayor precisión y detalle.

Obtenidos todos los datos, se procede a su contextualización histórica. Para ello, y con el monopolio de TVE como telón de fondo, se ofrece un recorrido por la historia de los concursos a la vez que se aporta una perspectiva de su producción con la que apreciar su paulatina profesionalización y la puesta en marcha de nuevas fórmulas de entretenimiento. El resultado final se resume en las conclusiones.

\section{Los primeros concursos}

El concurso ha sido considerado como uno de los estandartes de la programación de entretenimiento con una producción constante a lo largo de todas las etapas históricas de Televisión Española. Sin embargo, fueron los programas de variedades (juego, música, humor...) los que inauguraron las primeras e improvisadas parrillas de programación alzándose originariamente como los representantes del género de entretenimiento. El concurso evolucionaría hacia un carácter más autónomo y con mayor protagonismo debido a la invariable promoción de contenidos especialmente populares con los que la cadena conquistaba al público potencial. Hasta entonces, formaría parte de programas contenedores como sección o complemento a otros atractivos del espectáculo, especialmente de magacines, programas muy frecuentes en la programación experimental. Se trataba de formatos fáciles de producir con pocos recursos y con una duración indeterminada según la necesidad: "Desde el Paseo de la Habana se ofrecía una especie de macro magazine en el que cabía un poquito de todo limitado, sin embargo, a dos únicas fuentes: o se trataba de espacios tomados en vivo en el propio plató de televisión, o eran contenidos elaborados previamente en soporte cinematográfico" (Rodríguez y Martínez, 1992: 165).

Desde las primeras emisiones en 1956, los estudios del Paseo de La Habana, en Madrid, se convirtieron en el primer centro de producción al uso. Se trataba de un chalet reformado empleado como plató con gran escasez de recursos (también se albergaban diferentes estancias para ensayos, taller de montaje de decorados y oficinas de dirección y del personal) desde donde se emitía en directo. "Los inicios se caracterizan por la lucha por sacar adelante una programación muy por encima de las posibilidades técnicas y humanas disponibles, donde era preciso recurrir constantemente a la improvisación [...] La técnica de realización era muy radiofónica. Poco a poco se van incorporando elementos más cinematográficos (Carreras Lario, 2012: 65 - 88).

$\mathrm{Si}$, generalmente, para la puesta en marcha de la producción televisiva el medio radiofónico fue fundamental en la adaptación de fórmulas y estándares organizativos, para el concurso también fue un pilar esencial. La adaptación de la mecánica de jue- 
gos de éxito, especialmente de preguntas y respuestas, hizo que la televisión heredara el público de la radio a medida que se asentaban las bases de un lenguaje audiovisual todavía por desarrollar. Así, la televisión vivió inicialmente de los formatos y profesionales del medio radiofónico con la producción de espacios de radio televisados. José Luis Colina, responsable de la dirección de programación y encargado de las primeras emisiones desde el Paseo de La Habana (Baget, 1987:3) tenía muy claro tal propósito: "Cuando pusimos la televisión en marcha buscábamos hacer aquello que pudiese crear audiencia a base de gente famosa o contenidos que pudiesen interesar" (Rodríguez y Martínez, 1992). De este modo, la televisión en España fue concebida como un medio para el espectáculo y el entretenimiento donde el concurso cobraría especial protagonismo por su capacidad de atracción y por su eficacia para conseguir publicidad masiva, cualidad heredada de la radio.

El primer concurso autónomo fue El Enigma (1958) un sencillo juego de preguntas donde se debía resolver un misterio policiaco propuesto por Alfonso Lapeña, responsable de la producción de la cadena. La escasez de receptores de televisión y las desorganizadas emisiones provocó que el formato pasara desapercibido. Por entonces la parrilla de programación no presentaba unos criterios claros y definidos para su organización. La edición de la revista Telediario (1957; posteriormente conocida como Tele Radio) permitió la publicación semanal de la programación estableciendo las pautas para una parrilla más regulada. Sin un criterio establecido, y siguiendo los cánones de algunas televisiones europeas aunque con la diferencia de la presencia de publicidad/patrocinio debido a la financiación mixta vigente, Televisión Española comenzó emitiendo cuatro horas diarias: "Durante este año las retransmisiones se hicieron muy frecuentes: partidos de futbol, desfiles militares, ópera, etc. Destacan los dramáticos, informativos, variedades, concursos; empiezan los programas educativos con cursos de idiomas y hace su aparición el primer telefilm. Los filmados siguen teniendo gran peso" (Carreras Lario, 2012: 67).

Posteriormente, en 1958, con la paulatina consolidación de la programación, fue cuando el concurso consigue verdaderas cuotas de popularidad gracias al éxito de los espacios de variedades en los que se incluyeron como secciones. Este fue el caso de Telemímica, dentro del programa Festival Marconi, presentado por Ángel de Echenique. El concurso presentaba a un grupo de jóvenes participantes, que competían en un juego de preguntas que debían ser contestadas a través de gestos. Telemímica fue el primer juego que adaptó realmente su mecánica a la televisión, alejándose de la influencia radiofónica para ser un formato específicamente televisivo. La puesta en escena de su competición y la reacción entre los jugadores se concibieron como un nuevo atractivo para la producción de concursos (un reflejo de la vida misma, el superarse a sí mismo para ser el mejor o conseguir lo ambicionado) que la radio no podía transmitir tan fielmente.

En relación, François Jost y André Gaudreault (1995: 269) afirman que la atracción y el éxito de los concursos se deben a la correlación entre sus principios y algunos aspectos sociales fundados en la competición o la suerte. Además, el concurso se presenta como algo alternativo a las decisiones de la vida cotidiana atrayendo cada vez más a nuevos sujetos capaces de demostrar su valía (competición) en un nuevo uni- 
verso donde la fama y popularidad prima en pro del reconocimiento del público lo que, indirectamente, también aporta al género de entretenimiento. Igualdad de oportunidades pero no de habilidades (Fiske, 1997: 265).

Los concursos de talentos contribuyeron a tal fin. TVE programó de manera continuada (e incluso a la vez) espacios de noveles (talent show) como Hacia la fama (1958) o Caras nuevas (1958) donde el público en plató participaba en la elección de los mejores lo que advirtió la trascendencia de la relación del espectador con la televisión. El programa contaba con un aplausómetro que medía simbólicamente la intensidad de los aplausos de los presentes en plató; aspecto que vislumbró el protagonismo que posteriormente tendría el espectador con la televisión; eje principal de los programas concurso en los años venideros. Por otro lado, Caras nuevas buscaba nuevos locutores y presentadores para Televisión Española en un microespacio independiente dentro de la programación, al igual que las versiones propias de la radio. Adriano Rinoldi y Blanca Álvarez se encargaron de la presentación, al igual que lo hicieran en otros concursos, formando junto con Jesús Álvarez, Laura Valenzuela y Ángel de Echenique, el primer grupo de profesionales dedicados exclusivamente al entretenimiento.

La estrenada interactividad con la audiencia se asentó con Preguntas al espacio (1958), presentado por Laura Valenzuela, un juego de preguntas cuya novedad residía en responder por teléfono a preguntas sobre imágenes emitidas en directo que evidenció la evolución de las técnicas de producción en televisión y la cercanía con el espectador. A este formato, se unen Jugamos o Juegue usted con nosotros, Tele Match, Estudio fotográfico o Reto a su vista, todos ellos espacios autónomos con diferentes contenidos y juegos.

Por entonces, los concursos y el resto de programas de entretenimiento acusaban muchos fallos debido a la falta de profesionalización de los sistemas de trabajo en TVE. El realizador Fernando García de la Vega (en Baget, 1987: 28) afirma: "En aquella época no éramos realizadores de un programa concreto sino que nos responsabilizábamos un día completo [...] Así que hacíamos de todo: entrevistas, informativos programas de teatro, musicales concursos. Lo que hubiera ese día en la programación [...]. En aquella época yo recuerdo que venía a hacer una media de diez o doce programas semanales". De esta manera, los realizadores observaron la necesidad de una figura que coordinara el contenido y se responsabilizara del control creativo y organizativo: "Al no existir este tipo de individuo, capaz de imprimir su sello y personalidad propia a un determinado tiempo en antena, a un puro tiempo de emisión, los programas resultan neutros, sin garra, incapaces de resistir la acción exhaustiva de unas cuantas semanas de programación" (De las Casas, 1959: 273). Así, el perfil del productor se concibió como el máximo responsable del programa y cercano a la figura del realizador o director: "el productor de televisión no sólo 'realiza' un programa, sino que actúa de director escénico, de director artístico en términos teatrales, de director cinematográfico, esboza decorados, efectúa estudios e investigaciones sobre las materias del programa, en una palabra, es el director de orquesta de todos los medios técnicos y artísticos" (Aguilera, 1965: 24).

Para los productores, los concursos suponían una apuesta segura. Lacalle (2001: 47) destaca algunas ventajas como su bajo presupuesto, la sencillez de su puesta en es- 
cena, la escasez de recursos técnicos y humanos y la homogeneización del modelo de producción requerido que seguía los pasos de aquellos programas que sirvieron como referente a los españoles y a medio mundo: la producción estadounidense. Estados Unidos fue pionera en la exportación mundial de formatos de entretenimiento debido a la creación de espacios genéricamente adaptables. Los patrocinadores de los programas españoles (Marconi, Philips, Telefunken, Avecrem, Nescafé...) potenciaron tales adaptaciones enviando equipos de producción a las grabaciones extranjeras con el fin de introducir en España el abanico de concursos de éxito ya testados. Vila-San Juan (1981: 68-69), afirma: "La empresa patrocinadora del programa iba 'por libre' y no utilizaba, afortunadamente, ni parámetros estatales ni los procedimientos de televisión. Ella pagaba a TVE el alquiler de su tiempo en antena y corría con los gastos de la producción, quedando únicamente sujeta a una supervisión de los contenidos del programa". Fue común que algunos contenidos incluyeran los logotipos de los patrocinadores en el decorado o sus nombres como parte del título del programa. Su eslogan fue "un anuncio en televisión es un escaparate en cada hogar" (Telediario, $\mathrm{n}^{\circ} 18,1958$ ).

Generalmente, la mayoría de las producciones respondieron a los tres tipos básicos de concurso (Moreno et al., 2013: 106): conocimiento (quiz show), habilidad (chance show) y psicológicos (basados en desechar o elegir por puro azar; game). Matelsky (1992: 36) señala, además, otros tipos de juegos comunes a toda estructura y mecanismo de los concursos: Palabras (crucigrama televisado donde el participante forma nombres con las letras); Comunicación de palabra (personajes famosos acuden al programa para ayudar a los concursantes a que puedan ganar el premio final si adivinan la palabra o frase misteriosa); Puzle/Rompecabezas (contestar correctamente las preguntas para ir desvelando las pistas de un puzle escondido debajo de las láminas de un tablero o similar); Juegos en grupo (varios famosos conversan ingeniosamente con un invitado misterioso que guarda algún secreto); Gente (personas desconocidas, individualmente o en grupo, desvelan detalles personales comprometidos de ellos mismos o de sus parejas); Juego en fases (se responden a unas preguntas previas para girar una ruleta, tirar los dados, descubrir una carta...); Adivinanzas (se forman equipos para representar con gestos títulos de películas, canciones, melodías, frases...).

Junto a este tipo de clasificaciones, los concursos presentaban una serie de elementos comunes a todos los formatos cuyas fórmulas fueron heredadas de las producciones norteamericana. Les Brown (1982: 115) indica la presencia de un conductor que marca el ritmo del programa; presencia de público en plató; participación de concursantes externos al mundo televisivo; un conjunto de reglas que definen el tipo de competición; y la distribución de premios en metálico o regalos a los ganadores. Tales elementos fueron complementados por los atractivos de una puesta en escena basada en la presentación de variedades que, en progresión, convirtieron a los concursos en formatos potencialmente atractivos (game show). Esta hibridación fomentó su ubicación en la franja horaria nocturna (prime time) convirtiéndose en los programas estrella donde la función evasiva y numerosos atractivos (Imbert, 2003: 56) dominaba en su carácter que subrayaba la condición de la televisión como "esencialmente espectáculo" (Rodríguez Pastoriza, 2003: 84). 


\section{La espectacularización de los formatos}

En 1959, Televisión Española decidió descentralizar su producción de los estudios del Paseo de la Habana en Madrid inaugurando los estudios Miramar en Barcelona centrados en la producción de entretenimiento. Sus primeros concursos fueron adaptaciones americanas como X-O da dinero basado en Tic-Tac Dough (NBC) sobre el juego de las tres en raya o Adivinen su vida del programa de la cadena CBS What's my line?, donde se debía acertar la profesión de un personaje. Estas producciones auguraron el carácter espectacular que los concursos asumieron en la década de los sesenta gracias a la experiencia adquirida en las adaptaciones internacionales como por la evolución lógica de las técnicas de producción y lenguaje audiovisual.

La parrilla aumentó el número de horas y, en consecuencia, el de los concursos que comienzan a popularizar elementos clave: la figura de un participante que podía repetir en sucesivas emisiones (carryover contestant) cuyo recuerdo permitía a los espectadores identificarse cada semana con su gesta; la instauración de las llamadas telefónicas como articulación del ritmo de la dinámica en pro del aumento del suspense en el juego; y la figura de un presentador con un marcado carácter actoral. Así ocurrió en Ayer noticia, hoy dinero (1960), con Mario Beut, uno de los referentes. Se trataba de un juego preguntas y respuestas sobre noticias y acontecimientos publicados en la prensa mundial, que se convirtió en uno de los concursos más llamativo de la década de los sesenta.

Los concursos autónomos comenzaban a despuntar sobre los incluidos en otros programas. Ambos supieron complementarse y el público entendió dos fórmulas distintas en la representación de lo lúdico en televisión [desde los contenidos del de variedades Carrussel (1960) hasta el de adivinanzas Sí o no (1962)]. Su mayor diferencia estribó también en el plan de grabación y/o emisión. Muchos de los grandes invertían hasta cinco días para media hora de duración (como Peña Deportiva, de preguntas, debido a la búsqueda y selección de imágenes deportivas del archivo de NO-DO con los medios de la época). Además, muchos profesionales demostraron su versatilidad combinando a la vez funciones de dirección, producción e, incluso, realización.

En 1963, de las 75 horas semanales de emisión, ocho fueron para los concursos posicionándose como uno de los espacios familiares por excelencia. Desde el punto de vista de la producción, los concursos se realizaban en directo aunque el empleo del magnetoscopio para insertos, grabación por bloques o falso directo fue cada vez más común. También la incorporación de locutores de radio como presentadores fue constante y un atractivo con el que dar mayor repercusión mediática del programa. Su participación en uno u otro concurso sirvió para rivalizar entre las producciones de Madrid y Barcelona (además de por la puesta en escena, la dinámica de los juegos y la magnitud de los premios).

En 1964, se inauguran los estudios de Prado del Rey en Madrid con el plató, por entonces, más grande de Europa. Un nuevo espacio que permitió mejoras en el desarrollo de programas de gran envergadura con respecto a los anteriores. Esta novedad supone un antes y un después en la espectacularización de los concursos gracias a las mejoras tecnológicas y logísticas de las rutinas de producción. El primer gran concurso de referencia realizado fue La unión hace la fuerza (1964) donde intelectuales y de- 
portistas debían complementarse en diferentes pruebas representando a una provincia española. Es lo que Gordillo (2010: 79) denomina como "local game: programas en que la competencia no se organizaba a partir de concursantes individuales, sino que la rivalidad se ejercía en función de la localidad española que representaban. Esta fórmula habitual en muchos programas fue entendida como un acto propagandístico del Régimen para dar a conocer las virtudes de cada región).

La realización en interiores y exteriores (con la primera unidad móvil de TVE en exclusiva para un concurso) y el dinamismo de su mecánica generó una mayor sensación de espectáculo rompiendo con la formal puesta en escena hasta entonces. Estas nuevas pautas de producción sirvieron como modelo para futuros programas confirmando las posibilidades de los concursos de gran formato.

Barcelona amplía sus estudios y estrena Reina por un día (1964) basado en el programa Queen for a Day (1945, NBC) donde una persona anónima podía convertirse, tal y como indica su título, en reina por un día cumpliendo sus aspiraciones más deseadas. Esta producción presenta un contenido más propio de un reality show que de un juego al uso. Sin embargo, el concurso (reality game) radicaba en la selección de las participantes. El público comenzaba a identificarse con la vida de sus aspirantes convertidas ya en personajes propios de un serial radiofónico.

En 1965 se estrena el juvenil Cesta y Puntos con Daniel Vindel el cual ya había realizado un espacio similar en la radio. Basado en un partido de baloncesto, dos grupos de estudiantes representados por diferentes centros de enseñanza competían en diferentes fases respondiendo a preguntas ante un tribunal que daba o no por correctas las respuestas y aclaraba las dudas surgidas. Las marcas comerciales también participaron en su dinámica ofreciendo sus productos como regalos y asentando su colaboración como parte de la financiación del programa.

Un año después nace la segunda cadena. El UHF ofreció espacios más alternativos y culturales con respecto a los de la primera. A pesar de que su oferta de entretenimiento estaba basada más en los dramáticos programó espacios como Concurso de guiones (1966) donde tres realizadores de Miramar seleccionaban guiones propuestos por los espectadores para ser producidos; El juego de la Oca (1966) presentado por Joaquín Soler Serrano y basado en el juego de mesa donde los concursantes debían superar pruebas variopintas en relación a las casillas del tablero; el juego deportivo Concurso Naútico (1969) presentado por Mario Beut; y Palmo a Palmo (1970) con Teresa Gimpera y Rafael de Penagos, de preguntas sobre los diferentes puntos geográficos del país.

Las grandes producciones continuaron en el primer canal con Gran Premio (1966), basado en el francés Palmarés des Chansons (RTF, 1965) que mezcló el concurso con el espectáculo musical y deportivo sustituyendo al exitoso La unión hace la fuerza (1964). También se programó Danzas de España (1966) que seguía la dinámica de la competición entre provincias donde un jurado decidía el mejor baile regional combinando plató y exteriores. Además, y siguiendo con la idea de promocionar España, se realizan los concursos Kilométro Lanzado (1966) con juegos sobre rutas turísticas para dar un mejor conocimiento del país; Rimas populares (1969) donde se debía adivinar la palabra que faltaba en poesías o coplas de autores nacionales; Los hombres 
saben, los pueblos marchan (1969), eliminatorias de competición entre provincias cuyos concursantes podían ser ayudados hasta por su municipio; y Un pueblo para Europa (1970) en el que se elegía el representante español en el concurso internacional Juego sin fronteras.

Televisión Española siguió apostando por el concurso con formatos basados en los éxitos anteriores con una marcada desigualdad entre las producciones de prime time y los ubicados en franjas menos atractivas donde se evidenciaba el retraso tecnológico o narrativo con respecto a otros.

La cadena entendió que para seguir atrayendo al espectador (seducido también por los telefilmes y películas dobladas norteamericanas) debía seguir fortaleciendo la espectacularidad en la mejor franja. Así nació uno de los mayores referentes: Un millón para el mejor (1968) ideado por Enrique de las Casas y Fernando García de la Vega. La dinámica consistía en superar diferentes pruebas para ganar un millón de pesetas, desorbitada cifra para entonces pero que supuso un gran reclamo. Además el programa contó con Joaquín Prat (y posteriormente con José Luis Pécker) como anfitrión cuya animada forma de presentar, no vista hasta entonces, atisbó un nuevo papel del presentador de entretenimiento. Los concursantes consiguieron una popularidad desbordante que provocó mayor interés sobre el programa.

Posteriormente, los años setenta comenzaron con reediciones de éxitos de programas de talentos sin demasiado respaldo por el público. El primer referente fue En equipo (1970) presentado por José Luis Urribarri y Alfredo Amestoy, desde Miramar, donde un emprendedor defendía su idea ante un jurado que podría premiarle con una cantidad económica para llevar a cabo su actividad o empresa. Posteriormente, se emitiría Pasaporte a Dublín (1970) aprovechando la popularidad y aceptación de los musicales y del Festival de la Canción de Eurovisión el cual siempre ha sido uno de los formatos más representativos del entretenimiento ritual (una competición musical ente países donde España pudo demostrar su capacidad organizativa en 1969 tras la victoria un año antes). Pasaporte a Dublín (1970) bebió de la dinámica de los primeros talent shows pero con una gran dosis de espectáculo motivada por dos profesionales de referencia: Valerio Lazarov y Fernando García de la Vega. Presentado por Massiel y Julio Iglesias, el programa consistía en elegir al candidato que representara al país en el festival de la canción entre diez artistas de reconocido prestigio. El concurso seguía una estructura que acreditó su carácter de reality al combinar vídeos de la evolución de los participantes, actuaciones y las reacciones ante los desencuentros con el jurado encargado del veredicto final (elementos que se sumaron a las características de los concursos). También se emitieron Canción 71 (1971); La gran ocasión (1972) o Gente joven (1974).

Durante esta década, la multiplicación de televisores, espectadores y horas de emisión (complementadas con el UHF) configuraron al medio televisivo como un bien indispensable en los hogares de la clase media. Los concursos fueron abanderados de este fenómeno y de la relación televisión-espectáculo tal y como reflejó el referente Un, Dos, Tres... responda otra vez que comenzó a formar parte del imaginario colectivo televisivo desde su estreno en 1972. El concurso fue ideado por Narciso Ibáñez Serrador basándose en la unión de tres juegos (preguntas, habilidad y psicológico). Su 
estructura quedó dividida en la ronda de preguntas, la eliminatoria y la subasta cuya dinámica consistía en determinar qué pareja de concursantes participaban en el último bloque donde optar a un premio final. A medida que trascurría esta primer a etapa, se fueron incluyendo otros atractivo como una tematización semanal que atendía al interés de Ibáñez Serrador por la potencialidad de la puesta en escena y que justificaban elementos propios de un programa de variedades como coreografías, actuaciones musicales, representaciones escénicas, gags, humoristas...

Un, Dos, Tres... comenzó a mezclar el espectáculo con el concurso (game show) generando una marca de autor que perfeccionaría en sus diez etapas emitidas intermitentemente hasta 2004. Es lo que Imbert (2003:84) denomina como la ley de la variedad; propio de los formatos híbridos o contenedores de los años setenta "que convirtieron en referencia a los de los ochenta" (Calabrese, 1989:96) cuya imagen responde a los rasgos constitutivos y pertinentes de un "sistema estético y de significación" (Zunzunegui, 1989: 124).

Su presentador fue Kiko Ledgard, profesional peruano experimentado en programas similares [Haga negocio con Kiko, Panamericana TV (1969)] que obtuvo una gran popularidad gracias a su facilidad para llegar a una audiencia fascinada por la agilidad y espontaneidad de una presentación desligada del corsé radiofónico y que respondía al perfil americano de showman que se adaptaba perfectamente al tratamiento familiar del concurso. El presentador estaba acompañado de un grupo de secretarias que rápidamente se convirtieron en iconos del programa al igual que el personaje cómico Don Cicuta, caricatura del sistema político que personificaba a la censura abanderando valores negativos como alter ego de los concursantes.

"Hoy por hoy, Un, Dos, Tres... permanece imborrable en la memoria colectiva de muchas generaciones de espectadores lo que le convierten en el más popular y recordado de los trabajos de Ibáñez Serrador. El realizador supo construir magistralmente un universo propio cuyos dispositivos narrativos, comunicativos, lingüísticos y culturales generaron una extraordinaria dimensión comunicativa gracias a una reconocible y exclusiva marca de autor" (Moreno Díaz, 2009: 640).

El triunfo de Un, Dos, Tres... estimuló nuevas producciones (Las supersabias (1972) de la mano de Torrebruno en el que sólo las mujeres podían demostrar su sapiencia ante preguntas de gran dificultad o el infantil El juego de la foca (1972), con Guillermo Summers, en el que dos equipos debían superar diferentes pruebas a lo largo de un recorrido) pero con menor fortuna debido al recuerdo y a la comparación con el invento de Ibáñez Serrador.

En 1974 nace Cambie su suerte entendido (y promocionado) como el sucesor de Un, Dos, Tres... La apuesta estrella de la temporada con el que renovar la producción de entretenimiento. Se trataba de un concurso con reminiscencia a Un millón para el mejor (1968). De hecho sus presentadores también participaron en este nuevo programa basado en dos partes: una cultural (con Pécker) donde las preguntas se planteaban en tres pantallas y otra de habilidad (con Prat) donde el concursante tentado por el presentador cambiaba su suerte jugando en tales pruebas adornadas con actuaciones musicales, famosos, participación del público y, de nuevo, un millón de pesetas como premio final. Posteriormente, Televisión Española también estrena Todo es po- 
sible en domingo, un programa de variedades con juegos a cargo de Kiko Ledgard en recuerdo de la eliminatoria de Un, Dos, Tres... que vislumbra la preferencia de TVE por producciones híbridas en detrimento de los clásicos; un recurso constante en futuras décadas.

Posteriormente, se producirían otros espacios como ¿Lo conoce usted? (1975) presentado por Pedro Ruíz en torno a la figura de un personaje popular; A simple vista (1975) donde se planteaban preguntas relacionadas con el número de las cartas de la baraja española referido a cuatro temas; o Torneo (1975) en la línea de las producciones con Daniel Vindel sin demasiado éxito. No obstante, el concurso avanzó en relación al perfeccionamiento de la escenografía e iluminación debido a la puesta en marcha de la televisión en color que sirvió para mostrar una nueva dimensión.

Tras lo fallidos intentos en búsqueda de una nueva renovación, Televisión Española decide organizar para 1976 la segunda temporada de Un, Dos, Tres... (y así lo haría en otras temporadas como comodín de éxito) consolidándolo como el abanderado del entretenimiento público televisivo en España.

\section{Conclusiones}

La producción de formatos de entretenimiento en España se origina en el período comprendido entre 1956 y 1975. Durante estos años pioneros, el concurso se asienta progresivamente para fortalecerse como uno de los sustentos del atractivo de la televisión pública por el número de producciones y por el nivel de popularidad alcanzado por la mayoría de los formatos. En esta etapa en la que se mantiene el monopolio televiso nacional se programan juegos y concursos que responden a una producción de contenidos de servicio público y a favor del Régimen: contenido familiar; potenciación y promoción de la imagen del país; alarde de los valores nacionales; y gestión y financiación suficientes. De esta manera, la creatividad responderá más al enriquecimiento de la oferta e intereses patrios que a los industriales, económicos y empresariales. Este desinterés por el formato permitió cierta libertad a los diferentes profesionales implicados, a pesar del control ejercido. Especialmente en la puesta en marcha de contenidos genéricos lúdicos. No obstante, es importante destacar la influencia ejercida por parte de algunos patrocinadores a pesar de que no existan datos precisos de audiencias.

La evolución del concurso obedece a la propia del medio: de una producción primaria a una más competente y profesionalizada. A pesar del considerable mimetismo inicial, existe una desvinculación progresiva de la narrativa radiofónica. La radio marcó el inicio de la producción de concursos con las adaptaciones de algunos de sus programas hasta que la televisión modificó el proceso de producción gracias a las mejoras tecnológicas (en la década de los sesenta) para asentar exclusivos formatos por y para la pequeña pantalla. El lenguaje, los contenidos, los profesionales y los planes de producción organizaron una parrilla cuya planificación permitió una mayor y progresiva calidad en la técnica y en el contenido. Se pasó de los estudios madrileños del Paseo de La Habana a Prado del Rey incluyendo los estudios de Miramar en Barcelona dedicados exclusivamente a la producción de entretenimiento, lo que evidencia la apuesta por el género. 
Gracias a los patrocinadores y a su insistencia por las adaptaciones extranjeras, TVE ofreció nuevos formatos que sirvieron para potenciar el género tras contar con la experiencia de otras cadenas y productoras para el desarrollo de los contenidos. Esto supuso una nueva dimensión para futuros proyectos. Las marcas comerciales cobraron especial protagonismo. Marconi, Omo, Telefunken, Philips, Avecrem, Potax, Nescafé o Publicidad Cid fueron algunas de las empresas que participaron en la financiación de los programas cuyos productos suponían, en ocasiones, el regalo para los concursantes. El modelo de financiación mixta de TVE justificó su presencia.

La óptima conciliación del espectador a nuevas fórmulas y elementos narrativos determinan las razones en la evolución de la producción con la consecuente popularización de los concursos en respuesta a la hipótesis empleada inicialmente:

- Puesta escena basada en la desteatralización inicial para incorporar diferentes sets y decorados en platós (interiores y exteriores) cada vez de mayor capacidad que permitieran el mayor número de elementos como atractivo al medio audiovisual desde donde se produce (recursos como paneles o pantallas, público presente en plató, fragmentación en la realización, nuevas narrativas...).

- Producciones donde el público pudiera demostrar públicamente su aptitud, capacidad u orgullo patrio en mecánicas propuestas relacionadas con su implicación emotiva relacionado con el poder socializador de la pequeña pantalla. Especialmente en programas de búsqueda de talentos (Hacia la fama; Caras nuevas; Primer aplauso; En equipo; Gente joven...), los de competiciones entre provincias ( $\mathrm{La}$ unión hace la fuerza; Danzas de España; Los hombres saben, los pueblos marchan) o aquellos en los que había que demostrar la sapiencia a cambio de grandes premios (Un millón para el mejor, Cesta y puntos). Es importante destacar también la participación del espectador de casa en las dinámicas propuestas que empujaron al perfeccionamiento de las tecnologías (llamadas telefónicas en directo, por ejemplo) y que asentaron los pilares de la relación televisión-audiencia.

- Atractivos populares y materiales: Las grandes cifras de dinero, coches, apartamentos y demás galardones fueron fundamentales en la progresiva espectacularización del contenido. Lo mismo que el éxito de sus presentadores y participantes los cuales pasaron del anonimato a ser protagonistas, ídolos de masas y personajes creados por un inicial star system televisivo lo que argumenta la importancia de la selección de los mismos.

Con una disposición muy similar a la del resto de televisiones europeas, la programación nacional consolida progresivamente su estructura aumentando el número de horas y estableciendo franjas horarias más definidas (sobremesa, tarde, noche).En respuesta a esta evolución, los concursos experimentaron una producción desigual.

La mayoría de los concursos no sobrepasa los 120 minutos, son ubicados los fines de semana y especialmente en horario nocturno a pesar de la existencia de otros que complementaron las franjas diurnas de la primera cadena frente a la escasez del UHF.

Los años con mayor número de estrenos son 1958 (11), 1960 (9), 1961 (9), 1964 (9), 1969 (9) y 1972 (7). Junto a la justificación del atractivo popular con el que dar mayor protagonismo a la parrilla y el avance tecnológico expresado en nuevas instalaciones para la puesta en marcha de un mayor número de programas con mayor ca- 
lidad, se une el éxito arrollador de determinados formatos que promovieron la apuesta por contenidos similares. Así ocurre en 1964 con La unión hace la fuerza, en 1969 con Un millón para el mejor y en 1972 con Un, Dos, Tres... Alrededor de estas referencias se produjeron un mayor número de concursos con respecto a otras temporadas. No obstante, fue común que la producción decreciera considerablemente en los años venideros. El gran éxito de los referentes ensombreció a otros formatos que emplearon las mismas o parecidas fórmulas con las que asegurarse el reconocimiento de un espectador que realmente los concibió como versiones o copias del original. La falta de ideas determinada por la notoriedad de algunos formatos frenó la producción propia en cuantiosas ocasiones y a favor de otros géneros.

La condición de programas espectaculares confirmó el atractivo de los concursos como un reclamo más en horario estrella; fórmula que responde a la concepción que actualmente se tiene de la lógica comercial del prime time. La denominación de concurso estelar responde a la hibridación de diferentes atractivos. La mezcla de la estructura clásica de juegos genéricos (preguntas y respuestas, habilidad y psicológicos o de azar) unida a la esencia y amenidades de los programas de variedades, fueron decisivos para reforzar el carácter espectacular de la cadena.

Las fuentes de información para el estudio histórico de la evolución del género sirven, en conjunto, para tratar con detalle la dinámica de la mayoría de los concursos. A pesar de la escasa información anterior a 1960, los materiales consultados (especialmente la revista Telediario/Tele Radio) ofrecen una información exhaustiva de la programación y de los formatos de estreno y de aquellos que obtienen una repercusión social gracias a los datos suministrados por sus encuestas reflejadas en los paneles de aceptación de programas. Frente al papel, el material audiovisual visionado responde al escaso interés documental de entonces por conservar el material como interés sociocultural. Más en los formatos de entretenimiento que, en general, no suelen ser valorados con respecto a otros géneros. Programas incompletos, grabaciones encima de otras o fallos de sonido son algunos de los pormenores a los que enfrentarse aunque también han resultado relevantes.

En esta investigación se ha constatado la evolución del concurso como factor determinante en la producción de entretenimiento en TVE. Es interesante, en futuros estudios, profundizar en la anunciada industrialización y relación con productoras externas en la búsqueda de nuevos contenidos con los que seguir haciendo historia.

\section{Referencias}

AGUILERA GAMONEDA, Joaquín de (1965): La realización en televisión. Madrid, Imprenta del Servicio de Publicaciones del Ministerio de Información y Turismo.

AUGÉ, Marc (1998): La guerra de los sueños: ejercicios de etno-ficción. Barcelona, Gedisa.

BAGET HERMS, Josep Maria (1975): 18 años de TVE. Barcelona, Diáfora.

BAGET HERMS, Josep Maria (1987): "Historia de TVE", en Diario Ya: http://www.gestor.rtve.es/files/70-1484-FICHERO/Historia_de_TVE_Coleccionable_diarioYa.pdf> [fecha de consulta: 5 mayo 2006]. 
BROWN, Les (1982): Les Brown's encyclopedia of television. New York, Zoetrope.

CALABRESE, Omar (1989): La era neobarroca. Madrid, Cátedra.

CARRERAS LARIO, Natividad (2012): TVE en sus inicios. Madrid, Fragua.

ECO, Umberto (1985): Apocalípticos e integrados. Barcelona, Lumen.

FERRÉS, Joan (1996): Televisión Subliminal. Socialización mediante comunicaciones inadvertidas. Barcelona, Paidós.

GORDILLO, Inmaculada (2010): “En Trípodos, Vol. 19 (2013): “Del 'Responda otra vez' al 'Estás nominado'. Evolución y modelos de los concursos televisivos en España”. Trípodos, n²7. Barcelona, Universitat Ramon Llull, pp. 75-84

FISKE, John (1997): Television culture. London, Routledge.

HURTLEY, John (2000): Los usos de la televisión. Barcelona, Paidós Comunicación.

IMBERT, Gérard (2003): El zoo visual: de la televisión espectacular a la televisión especular. Barcelona, Gedisa.

JOST, François y GAUDREAULT, André (1995): El relato cinematográfico: cine y narratología. Barcelona, Paidós.

LACALLE, Charo (2001): El espectador televisivo: los programas de entretenimiento. Barcelona, Gedisa.

MATELSKI, Marilyn J. (1992): Programación diurna de televisión. Madrid, Instituto Oficial de Radio y Televisión.

MORENO DÍAZ, Julio (2009): El universo de Un, Dos, Tres... responda otra vez: claves de su éxito. Tesis doctoral, Madrid, Universidad Rey Juan Carlos. [Consulta: 22 noviembre 2013].

MORENO DÍAZ, Julio y MEDINA DE LA VIÑA, Elena (Coord., 2013): Principios básicos de producción en televisión. Madrid, OMM Editorial.

MORLEY, David (1996): Televisión, audiencias y estudios culturales. Buenos Aires, Amorrortu Ediciones.

RODRÍGUEZ MÁRQUEZ, Ignacio y MARTÍNEZ UCEDA, Juan (1992): La televisión: historia y desarrollo (Los pioneros de la televisión). Barcelona, Mitre.

RODRÍGUEZ PASTORIZA, Francisco (2003): Cultura y televisión: una relación de conflicto. Barcelona, Gedisa.

VILA-SAN JUAN, Juan Felipe (1981): La "trastienda" de TVE. Esplugas de Llobregat, Plaza \& Janés.

WOLTON, Dominique (1995): Elogio del gran público: Una teoría de la televisión. Barcelona, Gedisa.

ZUNZUNEGUI, Santos (1989): Pensar la imagen. Madrid, Cátedra. 